\title{
ESCOLA SEM PARTIDO? UMA BREVE REFLEXÃO SOBRE AS DISTORÇÕES ENTRE O QUE O PROJETO DE LEI PROPÕE E O QUE SE DIVULGA À SOCIEDADE
}

\author{
COSTA, Kelly Souza ${ }^{1}$
}

FRIGOTTO, Gaudêncio (org.). Escola "sem" partido: esfinge que ameaça a educação e a sociedade brasileira. Rio de Janeiro: UERJ, LPP, 2017. 144p.

Sem dúvida 2017 está sendo um ano de dificuldades para os professores exercerem seu oficio e seu direito de expressar e problematizar contextos políticos, principalmente para aqueles que lecionam disciplinas das áreas sociais e de humanidades, em virtude do contexto que nosso país atravessa e, principalmente, devido à polarização de opiniões e à intolerância com os posicionamentos diversos.

Essas dificuldades dizem respeito ao patrulhamento e monitoramento presentes dentro das escolas, feito por alunos e pais, motivados por várias "lideranças", tendo nas figuras de políticos, instituições religiosas e até de determinadas "celebridades" os impulsionadores para tais práticas.

Miguel Nacib, Procurador Geral do Estado de São Paulo, é o idealizador do Escola sem Partido. Segundo Nacib, o movimento surgiu em 2004 como uma resposta ao professor de História de sua filha por ter comparado Che Guevara a São Francisco de Assis. De maneira geral, o patrulhamento busca viabilizar o Projeto de Lei (PL) no 867/2015, do Sr. Izalci Lucas (Deputado do PSDB/DF), que "inclui, entre as Diretrizes e Bases da Educação Nacional, o Programa Escola sem Partido". Alegase que o objetivo do movimento é de garantir uma escola onde não haja fins políticos, ideológicos e partidários, além de defender os direitos dos pais sobre a educação moral de seus filhos. Entretanto, esse discurso vem carregado de propostas que, de fato, engessam e limitam os debates presentes nas escolas, impondo uma visão unilateral, rechaçando opiniões e, consequentemente, os profissionais que sejam divergentes às noções de educação defendidos pelo $\mathrm{PL}$, como forma de "garantir" a não interferência na educação e nos valores familiares.

O livro Escola "Sem" Partido: esfinge que ameaça a educação e a sociedade brasileira, organizado pelo filósofo e pedagogo Gaudêncio Frigotto vem elucidar algumas questões centrais sobre o que vem a ser esse movimento. Identifica sua origem, passando por suas propostas declaradas e veladas, abordando incoerências nos discursos que mostram suas reais intenções, até chegar à abordagem dos reflexos diretos para a educação e para a prática docente que sua propagação pode

\footnotetext{
${ }^{1}$ Mestranda do Programa de Pós-Graduação de Ensino em Educação Básica, Instituto de Aplicação Fernando Rodrigues da Silveira da Universidade do Estado do Rio de Janeiro (CAp-UERJ), Bacharel e Licenciada em Geografia pela mesma Universidade. e-mail: kellycostageo@gmail.com
} 
trazer às escolas brasileiras. O livro possui uma bela apresentação e nove textos críticos e bastante esclarecedores.

A apresentação do livro é feita pela Professora Maria Ciavatta de maneira bastante didática. Em sua apresentação, a pesquisadora convida o leitor a uma reflexão da necessidade de se inteirar da acusação de patrulhamento ideológico que permeia as escolas do nosso país, tendo na figura do professor seu principal alvo. A autora faz um breve resumo dos capítulos do livro, expondo como as perspectivas abordadas se conectam e se complementam.

O primeiro artigo é de autoria de Frigotto - $A$ gênese das teses do Escola sem Partido: esfinge e ovo da serpente que ameaçam a sociedade e a educação - que desde o início deixa claro que a própria expressão "sem partido" é de um cinismo enorme, uma vez que a escola proposta busca nitidamente ser unilateral, deixando de abordar tudo que venha a ameaçar aos interesses de determinados grupos dominantes. Reforça que essa interferência no processo educacional abala a condição da escola como o lugar de formação humana, de convívio social, de liberdade e de respeito às diversidades, inclusive de pensamento. Aponta como o conservadorismo de determinados segmentos sociais está abalando o ato de ensinar e educar, além de enfatizar como o movimento Escola sem Partido está transformando pais e responsáveis em delatores daqueles que abordam temáticas não simpáticas ao movimento. O autor faz uma profunda reflexão sobre a escalada da lógica capitalista e da posição do Brasil nesse contexto, destacando o papel da educação como uma possível ameaça aos interesses do grande capital e das forças políticas neoconservadoras que estiveram por traz do golpe atual à nossa democracia.

No segundo, O Escola sem Partido como chave de leitura do fenômeno educacional, Fernando Araújo Penna alerta de que esse discurso defendido pelo movimento Escola sem Partido não é tão novo como alguns podem supor, pois data de 2004. Destaca que muitos de nós, profissionais da educação, não nos damos conta do perigo iminente desse movimento, o que nos leva a não o considerarmos sério como deveríamos, da mesma forma que não percebemos seu rápido crescimento. O autor esmiúça alguns de seus aspectos importantes, levando em conta 4 argumentos discursivos como pilares: (10) a concepção de escolarização, dissociando 0 ato de educar de instruir; (20) a desqualificação do professor, mesmo que isto fira a Convenção Americana sobre Direitos Humanos, e a ênfase de uma lógica mercadológica na escola, com o pai cliente, baseada no Código de Defesa do Consumidor; ( $\left.3^{\circ}\right)$ estratégias discursivas fascistas, acusando a escola de contaminação ideológica e os docentes de militantes travestidos de professores, alimentando o clima de denuncismo e o discurso de ódio; (40) a defesa do poder total dos pais sobre os filhos.

Em Breve análise sobre as redes do Escola sem Partido, Betty Solano Espinosa e Felipe Campanuci Queiroz, realçam como a onda conservadora que está sobre o 


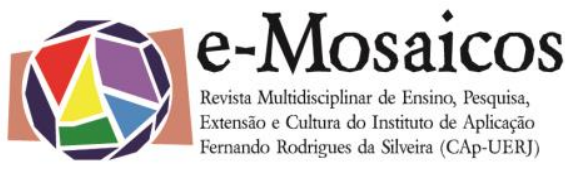

DOI: $10.12957 /$ e-mosaicos.2017.30267

país vem atacando a escola e buscando até interferir em alguns conteúdos e abordagens, como a teoria da evolução e a própria política de tolerância de gênero. Apesar do movimento Escola sem Partido ter princípios inconstitucionais e fundamentações frágeis, sua abrangência na sociedade ganhou proporções que não podem ser desconsideradas. Os autores buscam na Análise de Redes Sociais (ARS) uma quantificação e qualificação dos atores e dos eventos relacionados às temáticas defendidas pelo Escola sem Partido para saber as proporções de adesões e compartilhamentos dessas ideias. Mostram também como o caráter supostamente apartidário é falso, a partir das relações feitas entre os defensores do Escola sem Partido e os do impeachment da Presidenta Dilma Roussef.

Eveline Algebaile, no quarto artigo intitulado Escola sem Partido: o que é, como age, para que serve, busca reconhecer e identificar o movimento a partir de suas funções e modo de agir dentro desse contexto de regressão política e democrática que estamos passando. Destaca seus principais representantes e as conexões com a mídia, partidos políticos e instituições. Aborda suas ações e as principais temáticas/assuntos alvos e reforça seus interesses de controle jurídicopolítico sobre a escola.

No artigo Escola sem Partido: a criminalização do trabalho pedagógico, Marise Nogueira Ramos nos alerta para a realidade de algumas localidades que, em escala municipal ou estadual, já aprovaram projetos com o mesmo teor do PL no 867/2015. Ao expressar quais grupos apoiam o PL e quais as temáticas estão sob a mira dos ataques (raça e etnia, religiosidade, sexualidade, gênero, capitalismo e socialismo) a autora faz uma reflexão sobre o estado de exceção vivido atualmente e a tentativa de dissociar o ato educacional de seu viés político e da formação de uma sociedade politizada. Marise Ramos conclui alertando que, por mais que já se tenha comprovado a inconstitucionalidade do movimento e do $\mathrm{PL}$, o que mais preocupa é a conivência e o apoio cada vez maior de segmentos da sociedade com esses ideais de educação.

Em Educação e liberdade: apontamentos para um bom combate ao projeto de lei Escola sem Partido, o coletivo de autores considera como se deu a expansão do movimento, destacando a atuação das figuras políticas envolvidas e as estratégias apontadas para a defesa do PL. A forma vaga como se aborda a democracia, a noção de qualidade e de igualdade, assim como o uso de palavras de forte apelo social, capturam o apoio de parcelas da sociedade, sem esclarecer os reais sentidos e significados do discurso defendido.

O artigo Escola sem Partido: visibilizando racionalidades, analisando governamentalidades, de Isabel Scrivano Martins, Fabiana Lopes da Cunha e Pedro Paulo Bicalho explicam os motivos que levaram o movimento a vir a ganhar expressão tanto tempo depois de sua origem, relacionando com a conjuntura política recente do país. Busca ressaltar como as forças políticas conservadoras se apropriam do discurso de cuidado para controlar, dominar e garantir as diretrizes do mercado. 


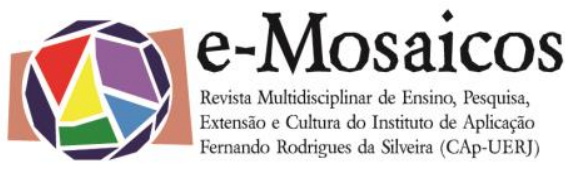

DOI: $10.12957 /$ e-mosaicos.2017.30267

Afirmam que essa censura travestida de cuidado compromete a relação professoraluno, atuando como ação restrita às escolas públicas, já que os contratos garantem às escolas particulares a manutenção de suas metodologias e abordagens de temáticas, de acordo com o estabelecido em contrato. Aqui faço uma ressalva sobre o que os autores discutem. Como professora de escola particular percebo que temos sofrido igual ou mais fortemente as acusações de doutrinadores por parte de pais e responsáveis "consumidores" e "clientes".

Rafael de Freitas e Souza e Tiago Fávero de Oliveira, no artigo $A$ doxa e o logos na educação: o avanço do irracionalismo, a partir de reflexões históricas, filosóficas e sociológicas analisam a incoerência na exigência feita aos professores em ensinar ciência (logos = razão) e os conhecimentos paralelos (doxa = opinião, crença comum) a cada teoria e conteúdo ensinados. Dessa forma, os autores não creem no PL como a busca pela imparcialidade do discurso ou no pluralismo de ideias, mas sim na disseminação de dogmas religiosos e de preconceitos anticientíficos. As salas de aula terão que abrir espaço para opiniões como verdades. Essas opiniões podem ser verdades estabelecidas em outras esferas de conhecimento, não no que se propõe na relação ensino-aprendizagem dentro do âmbito escolar. A apresentação de outras formas de conhecimento, o respeito a posicionamentos diversos, à individualidade, à liberdade e à tolerância fazem parte da Lei de Diretrizes e Bases da Educação Nacional, e deve ser mantida. Por isso, é importante explicitar a diferença entre a razão, senso comum e conhecimento religioso. Separar doxa de logos sempre gerou tensão, e, mais uma vez, estamos nesse embate. $\mathrm{O} \mathrm{PL}$, de acordo com a tese central dos autores, opta pela doxa em detrimento do logos, limitando a atuação do professor e do próprio conhecimento. Os autores terminam enfatizando a importância da escola em tomar partido, destacando a sua responsabilidade de formar cidadãos, transformadores sociais em busca de um mundo mais justo.

No último artigo, Reestruturação curricular no caminho inverso ao ideário Escola sem Partido, Paulino José Orso amarra todo o debate anterior ao destacar como a escola vem sofrendo um verdadeiro desmonte, ao desvalorizar os profissionais que nela trabalham e não ser mais o espaço fomentador de trocas que viabilizem os atos de ensinar, aprender e educar. Destaca como essa conjuntura vem abalando os projetos político pedagógicos e a própria reestruturação do currículo, todos sendo alinhados na direção dos interesses dominantes dentro da lógica do capital.

O esclarecimento sobre essas temáticas não deve se limitar ao ambiente escolar, aos profissionais de ensino ou aos responsáveis, uma vez que a remodelação da educação traz consequências diretas para toda a sociedade. Que futuro almejamos? Como gostaríamos de nos relacionar com o outro? Que tipo de sociedade buscamos? Essas questões parecem vagas e distantes, mas estão no cerne do projeto imposto pelo PL no 867/2015 e do movimento Escola sem Partido, 
com propostas muito bem estruturadas, até no que parece ser vago (o propósito pode ser esse mesmo, aliás). Cabe aos que atuam diretamente com a educação, seja ela pública ou privada, assumir uma postura crítica e efetiva ao movimento Escola sem Partido e à proposta do $\mathrm{PL}$, deixando claro seu caráter cerceador do ensino propriamente dito. Devemos sair da inércia e da acomodação que nos torna cúmplices por omissão. Cabe a nós, educadores, assumirmos nosso papel e divulgarmos à sociedade para que esta não compre "gato por lebre". Não basta falarmos para nós mesmos, para nossos pares escutarem. Faz-se necessário conhecer a proposta, identificar as ameaças, divulgar as incoerências e lutar pelo debate e por uma educação libertadora de fato. Educar para libertar, nunca esquecer o nosso papel. 